\title{
The Role of Surgical Resection Following Tyrosine Kinase Inhibitors Treatment in Patients with Advanced Gastrointestinal Stromal Tumors: A Systematic Review and Meta-analysis
}

\author{
Yinghao Guo 1,2, Jinqiang Liu1,3, Fei Wang1,4, Qiao Wang1,5, Gaozan Zheng1, Shushang Liu1, Xiao Lian¹, \\ Hongwei Zhang ${ }^{1 凶}$, Fan Feng ${ }^{\circledR}$ \\ 1. Department of Digestive Surgery, Xijing Hospital of Digestive Diseases, the Fourth Military Medical University, 127 West Changle Road, 710032 , Xi' an, \\ Shaanxi, China. \\ 2. Health company, 92667 Army of PLA, 39 East Zaoshan Road, 266100, Qingdao, Shandong, China. \\ 3. Cadre' s sanitarium, 62101 Army of PLA, 67 Nahu Road, 464000, Xinyang, Henan, China. \\ 4. Department of General Surgery, No. 534 Hospital of PLA, West Lichun Road, 471000, Luoyang, Henan, China. \\ 5. Department of General Surgery, No. 91 Hospital of PLA, 239 Gongye Road, 454000, Jiaozuo, Henan, China.
}

$\triangle$ Corresponding author: Hongwei Zhang, PhD, Department of Digestive Surgery, Xijing Hospital of Digestive Diseases, the Fourth Military Medical University, 127 West Changle Road, 710032, Xi'an, Shaanxi, China. Tel: +86-029-84771531. Fax: +86-029-84771531. Email: zhanghwfmmu@126.com; Fan Feng, MD, Department of Digestive Surgery, Xijing Hospital of Digestive Diseases, the Fourth Military Medical University, 127 West Changle Road, 710032, Xi'an, Shaanxi, China. Tel: +86-029-84771531. Fax: +86-029-84771531. Email: surgeonfengfan@163.com.

(c) The author(s). This is an open access article distributed under the terms of the Creative Commons Attribution License (https://creativecommons.org/licenses/by/4.0/). See http://ivyspring.com/terms for full terms and conditions.

Received: 2019.06.03; Accepted: 2019.08.16; Published: 2019.10.06

\begin{abstract}
Background The benefit of surgical resection for advanced gastrointestinal stromal tumors (GISTs) following tyrosine kinase inhibitors (TKIs) treatment was still under debate. The present meta-analysis was designed to assess the value of surgical resection for the prognosis of patients with metastatic, recurrence and unresectable GISTs. Methods A systematic search of PubMed Central, PubMed, EMBASE and the Cochrane Library database was performed. Relevant studies of the role of surgery in advanced GISTs published before 1 May 2019 were identified. The quality of studies was assessed by the Newcastle-Ottawa Quality Assessment Scale. The progression-free survival (PFS) and overall survival (OS) were assessed through software Stata 15.0. Results A total of 6 retrospective studies including 655 patients were analyzed. The pooled result revealed that surgical resection group was associated with better PFS (HR = 2.08; $95 \% \mathrm{Cl}: 1.58$ to $2.76 ; \mathrm{P}<0.001)$ and better $\mathrm{OS}(\mathrm{HR}=2.13 ; 95 \% \mathrm{Cl}$ : 1.59 to 2.85; $\mathrm{P}<0.001)$ compared with TKIs treatment alone group. Conclusions Surgical resection following TKIs treatment could significantly improve the prognosis of patients with advanced GISTs.
\end{abstract}

Key words: Gastrointestinal stromal tumor; Tyrosine kinase inhibitor; Surgery; Meta-analysis

\section{Introduction}

GISTs are the commonest mesenchymal tumors of the gastrointestinal tract, with an incidence range from 6.8 to 19.7 per million [1-3]. GISTs can arise anywhere within the gastrointestinal tract but most commonly in the stomach, followed by small intestine $[4,5]$. Approximately $85 \%$ of GISTs harbor a gain-of-function mutation in either KIT or platelet-derived growth factor receptor alpha (PDGFRA) genes [6-8]. GISTs could display a broad spectrum of clinical behavior, from benign to malignant [9].

For localized GISTs, complete resection remains the standard treatment, and surgery combination with TKIs treatment could significantly improve survival of patients. However, approximately $30 \%$ to $50 \%$ of patients will suffer from recurrence or metastasis within 3 years in absence of TKIs therapy [10-12]. Moreover, up to $50 \%$ of GISTs are metastatic 
or unresectable at the time of diagnosis[4, 13]. For these patients, imatinib was considered as first line treatment. The induction of imatinib has significantly improved the survival of patients with metastatic, recurrent and unresectable GISTs[14-16]. However, approximately $15 \%$ of patients were primarily resistant to imatinib treatment $[17,18]$. Although up to $80 \%$ of patients were initially responsive to imatinib treatment, most patients will develop secondary resistance resulting from secondary mutations within 2 years[19, 20]. In addition, approximately $20 \%$ of patients do not tolerate TKIs treatment[21-23]. Thus, surgical resection may be an additional option for metastatic, recurrent or unresectable GISTs, as it could decrease the tumor burden of patients. Over the last two decades, a series of studies[24-28] have demonstrated that surgical resection could improve the clinical outcomes of patients with advanced GISTs following TKIs therapy. Nevertheless, conflicting data has also been reported[29].

Therefore, the present study aims to investigate the clinical benefits of surgical resection following TKIs treatment for patients with metastatic, recurrent or unresectable GISTs through a systematic review and meta-analysis.

\section{Methods}

A systematic electronic search of PubMed Central, PubMed, EMBASE and the Cochrane Library was performed with language restriction to English to identify eligible studies published from the inception dates to May 1, 2019, utilizing the following combined Medical Subject Headings (MeSH) terms and relevant text words: 'gastrointestinal stromal tumors', 'GIST', 'GISTs', 'recurrence', 'advanced', 'metastasis', 'surgery', 'resection', 'cytoreduction,' and 'palliative'. Additionally, reference lists of review articles, commentaries, editorials, identified studies and conference proceedings were hand searched and cross-referenced to identify any other relevant data.

Two reviewers (GYH and LJQ) independently assessed the studies using the following inclusion criteria: (1) Diagnosed as recurrent, metastatic or unresectable GISTs; (2) The studies contain two groups: surgical resection group (S group) and TKIs treatment alone group (NS group); (3) In S group, surgical resection should be performed following TKIs treatment; (4) The informative data were available; and (5) Published in English. Disagreements were settled by consultation or adjudicated by a third reviewer (WF). Titles and abstracts were used to screen for initial study inclusion. Full-text review was performed when abstracts were insufficient to determine if the study met inclusion criteria or not.
Two researchers (ZGZ and LSS) independently extracted the following variables from each included study: the first author, years of survey, country of origin, study design, sample size, follow-up duration, outcomes (OS and PFS), median age, gender, primary tumors sites, metastases site, response to TKIs and genotype.

The quality of the included papers was assessed using the Newcastle-Ottawa Quality Assessment Scale (NOS) [30]. The risk of bias was deemed to be high if a study scored 0-3, moderate if it scored 4-6 and low if it scored 7-9.

\section{Statistical analysis}

This meta-analysis was performed according to the Preferred Reporting Items for Systematic Reviews and Meta-Analyses (PRISMA) guidelines[31] (Supplementary Table S1). The primary outcomes were progression-free survival (PFS) and overall survival (OS). Hazard ratio (HR) and 95\% confidence intervals (CIs) were used to analysis time-to-event outcomes, if not reported, we derived HR and 95\% CIs based on data reconstructed from Kaplan-Meier survival curves reported by Tierney et al[32]. The surgical resection group was settled as "reference" group. A HR $>1$ indicated a worse prognosis in patients with advanced GISTs. Heterogeneity were estimated using the $\mathrm{I}^{2}$ statistic and the Cochrane $\mathrm{Q}$ test[33]. An I ${ }^{2}$ statistic was interpreted to reflect low heterogeneity $(0 \%-25 \%)$, moderate heterogeneity $(26 \%-75 \%)$, and high heterogeneity $(76 \%-100 \%)$, as was a $\mathrm{P}$ value of less than or equal to 0.05 for heterogeneity. Where there was a moderate or high likelihood of heterogeneity, sensitivity analyses were done to seek the reasons for the differences. The fixed-effect model was first fitted for all outcomes, if the $\mathrm{p}$ value of the heterogeneity $\mathrm{Q}$ test was greater than 0.1 ( $\left.\mathrm{I}^{2} \leq 40\right)$, the random effects model was used.

Publication bias was assessed by visual inspection of the funnel plot. The Begg's[34] and Egger's test[35] were used to identify asymmetry of funnel plots and significant publication bias was defined as a $p$ value $<0.1$.

Statistical software Stata (version 15.0) was used for data management and analysis. A two-sided $p$ value less than 0.05 were considered statistically significant.

\section{Results}

\section{Enrolled studies and quality assessment}

A total of 36270 studies (PubMed Central, $\mathrm{n}=27096$; PubMed, $\mathrm{n}=2841$; EMBASE, $\mathrm{n}=6133$; Cochrane library, $n=200$ ) were identified using our search strategy, of which six retrospective 
studies[36-41] were included in this meta-analysis. A flow chart of the search strategy and reasons for exclusion are illustrated in Figure 1.

The 6 studies enrolled 655 patients, of which 239 patients underwent surgery following TKIs therapy and 416 patients underwent TKIs treatment alone. The publication year ranged from 2005 to 2018. The recruitment time was between 2001 and 2016. Characteristics of the included studies were provided in Table 1 (Supplementary Table S2).

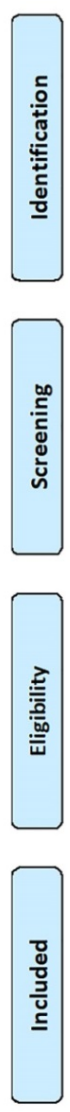

Records identified through database searching ( $\mathrm{n}=36270$ )

Records from PMC ( $n=27096)$

Records from PubMed $(n=2841)$

Records from EMBASE ( $n=6133$ )

Records from Cochrane Library $(n=200)$

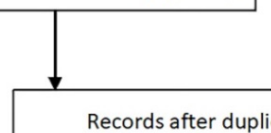

Additional records identified through other sources $(n=0)$

$$
(n=0)
$$

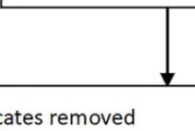
$(n=33265)$

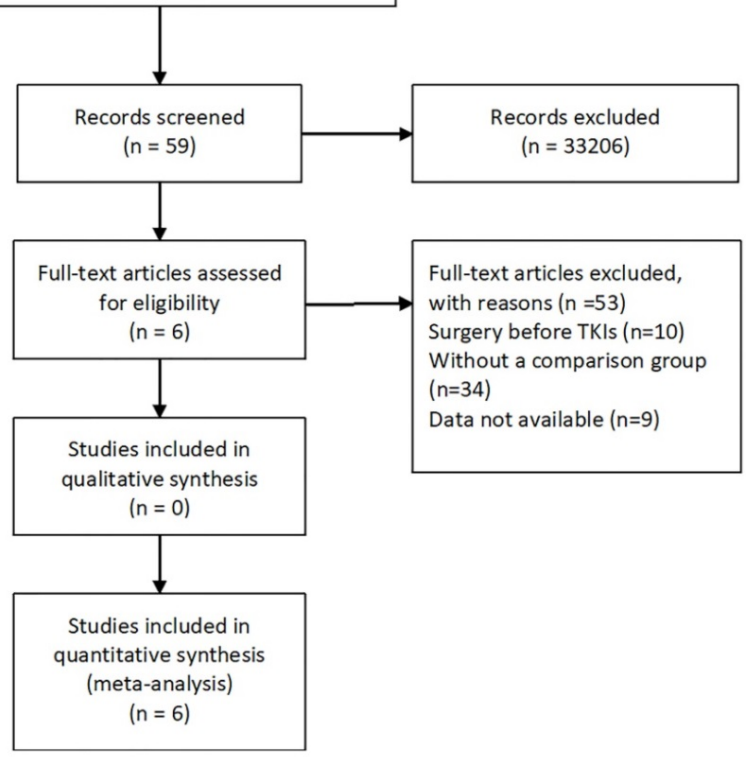

Figure 1 Flow chart of literature selection process.

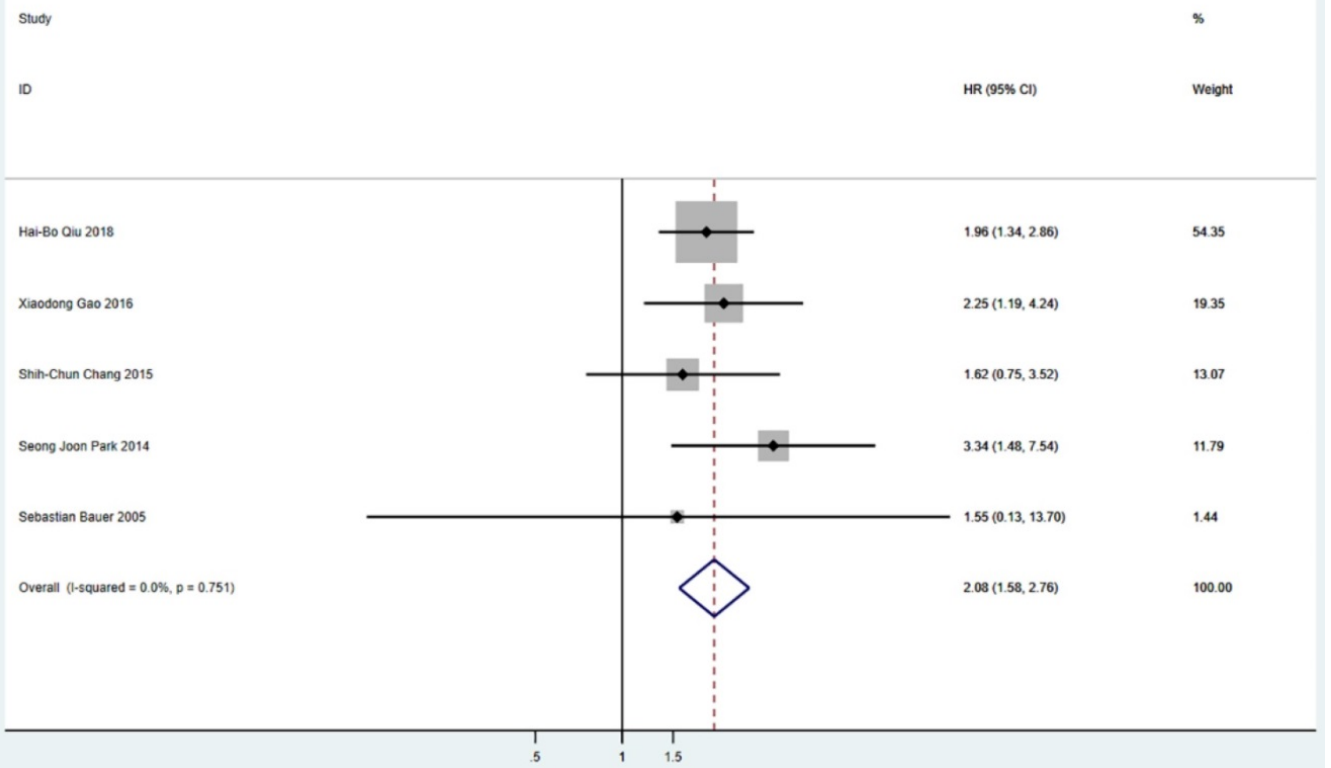

Figure 2 Meta-analysis of PFS between S group and NS group. PFS=progression-free survival, HR=hazard ratio, $\mathrm{Cl}=$ confidence interval, I-squared=the percentage of total variation across studies that is due to heterogeneity rather than chance. 
Table 1. Summary of studies included in the meta-analysis

\begin{tabular}{|c|c|c|c|c|c|c|c|c|c|}
\hline \multirow[t]{2}{*}{ Author } & \multirow[t]{2}{*}{ Year } & \multirow[t]{2}{*}{ Study period } & \multirow[t]{2}{*}{ Country } & \multirow[t]{2}{*}{ Study design } & \multicolumn{3}{|c|}{ Sample size } & \multirow{2}{*}{$\begin{array}{l}\text { Follow-ups } \\
\text { Median, range }\end{array}$} & \multirow[t]{2}{*}{ Outcomes } \\
\hline & & & & & Total & S group & NS group & & \\
\hline Hai-Bo Qiu & 2018 & $2002-2008$ & China & Retro & 156 & 87 & 69 & $23.7,3-81.5$ & PFS OS \\
\hline Hyungwoo Cho & 2018 & 2003-2016 & Korea & Retro & 90 & 38 & 52 & 31.0, NR & TTF OS \\
\hline Xiaodong Gao & 2016 & $2005-2014$ & China & Retro & 57 & 38 & 19 & $26.0,8-104$ & PFS OS \\
\hline Shih-Chun Chang & 2015 & $2001-2013$ & Taiwan & Retro & 128 & 22 & 106 & NR & PFS OS \\
\hline Seong Joon Park & 2014 & $2001-2010$ & Korea & Retro & 134 & 42 & 92 & $58.9,15.4-129.1$ & PFS OS \\
\hline Sebastian Bauer & 2005 & 2001-2004 & Germany & Retro & 90 & 12 & 78 & $29.8,17-41$ & PFS OS \\
\hline
\end{tabular}

Retro: retrospective study; TTF: time to IM treatment failure; PFS: progression-free survival; OS: overall survival; NR: not reported.

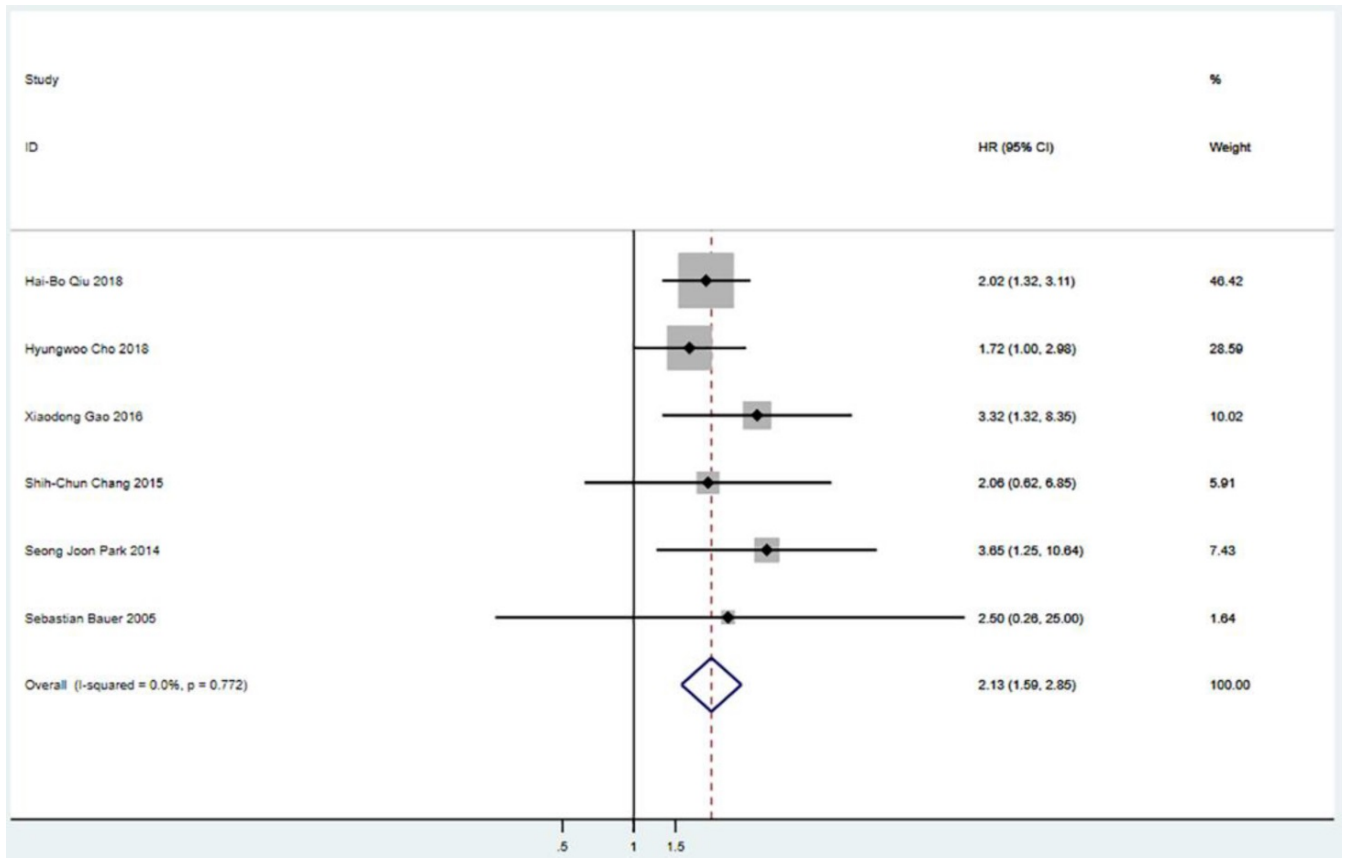

Figure 3 Meta-analysis of OS between S group and NS group. OS=overall survival, $\mathrm{HR}=$ hazard ratio, $\mathrm{Cl}=$ confidence interval, $\mathrm{l}$-squared=the percentage of total variation across studies that is due to heterogeneity rather than chance.

The quality assessment results of the included studies are shown in Table 2. All six articles were scored $\geq 7$, which ensured the high quality of the included articles.

Table 2. Newcastle-Ottawa Scale Assessment of enrolled studies

\begin{tabular}{|c|c|c|c|c|c|c|c|c|c|c|}
\hline \multirow[t]{2}{*}{ Ref } & \multicolumn{4}{|c|}{ Selection (0-4) } & \multicolumn{2}{|c|}{$\begin{array}{l}\text { Comparability } \\
(0-2)\end{array}$} & \multicolumn{3}{|c|}{ Outcome (0-3) } & \multirow[t]{2}{*}{ Total } \\
\hline & $\begin{array}{l}\text { RE } \\
\mathrm{C}\end{array}$ & Snec & $\mathrm{AE}$ & OINP & SCB & SCA & $\begin{array}{l}\mathrm{A} \\
\mathrm{O}\end{array}$ & FU & AFC & \\
\hline Hai-Bo Qiu & 1 & 1 & 1 & 1 & 1 & 1 & 1 & 1 & 1 & 9 \\
\hline $\begin{array}{l}\text { Hyungwoo } \\
\text { Cho }\end{array}$ & 1 & 1 & 1 & 1 & 0 & 0 & 1 & 1 & 1 & 7 \\
\hline $\begin{array}{l}\text { Xiaodong } \\
\text { Gao }\end{array}$ & 1 & 1 & 1 & 1 & 1 & 0 & 1 & 1 & 1 & 8 \\
\hline $\begin{array}{l}\text { Shih-Chun } \\
\text { Chang }\end{array}$ & 1 & 1 & 1 & 1 & 0 & 1 & 1 & 1 & 1 & 8 \\
\hline $\begin{array}{l}\text { Seong Joon } \\
\text { Park }\end{array}$ & 1 & 1 & 1 & 1 & 0 & 0 & 1 & 1 & 1 & 7 \\
\hline $\begin{array}{l}\text { Sebastian } \\
\text { Bauer }\end{array}$ & 1 & 1 & 1 & 1 & 1 & 0 & 1 & 1 & 1 & 8 \\
\hline
\end{tabular}

\section{Survival outcomes}

Five studies including 565 patients reported PFS. The pooled analysis revealed a better PFS for the surgical resection group than that in the TKIs treatment alone group ( $\mathrm{HR}=2.08 ; 95 \% \mathrm{CI}$ : 1.58 to 2.76 ; $\mathrm{P}<0.001$ ) (Figure 2). Six studies including 655 patients suggested that surgical resection group was associated with a better OS compared to TKIs treatment alone group ( $\mathrm{HR}=2.13 ; 95 \% \mathrm{CI}: 1.59$ to 2.85; $\mathrm{P}<0.001$ ) (Figure 3).

\section{Publication bias}

Publication bias was evaluated based on the funnel plot (Figure 4,5) using the Begg's and Egger's test. No publication bias was identified in the six studies.

\section{Discussion}

Despite most GISTs patients initially benefit from TKIs therapy, secondary resistance occurs at a median time of 2 years, which result in poor 
prognosis. Therefore, surgical resection for advanced GISTs is thought to be an additional therapy to remove residual tumor or drug resistant clones to induce remission or curation. However, the value of surgical resection for this situation was still under debate. Thus, the present meta-analysis was performed to evaluate the value of surgical resection for the prognosis of patients with metastatic, recurrent, or unresectable GISTs. Our pooled analysis demonstrated that GIST patients who treated with surgery following TKIs therapy showed better clinical outcomes in terms of PFS and OS compared with that received TKIs therapy alone.

Although randomized controlled trials (RCTs) are the first choice for meta-analysis, the RCTs focused on this point are insufficient for meta-analysis. One from the European Organization for Research and Treatment of Cancer (EORTC,
NCT00956072) [42]aimed to evaluate the value of cytoreductive surgery for imatinib-sensitive GIST patients was stopped after recruiting only 12 patients without any conclusions. One from China (CTR-TRC-000000344) [43] compared the survival of patients with peritoneal metastasis between surgery group (19 patients) and imatinib treatment alone group (22 patients) also terminated due to poor accrual. However, the PFS showed a trend towards survival benefit in the surgery arm, but no statistically significant difference was reached. The other one from China [44] compared the survival of patients with liver metastasis between surgery group (19 patients) and imatinib treatment alone group (20 patients) suggested that surgery combined with imatinib treatment could significantly improve the OS of patients, especially in poor responders. The results of the two RCTs were consistent with our present study.

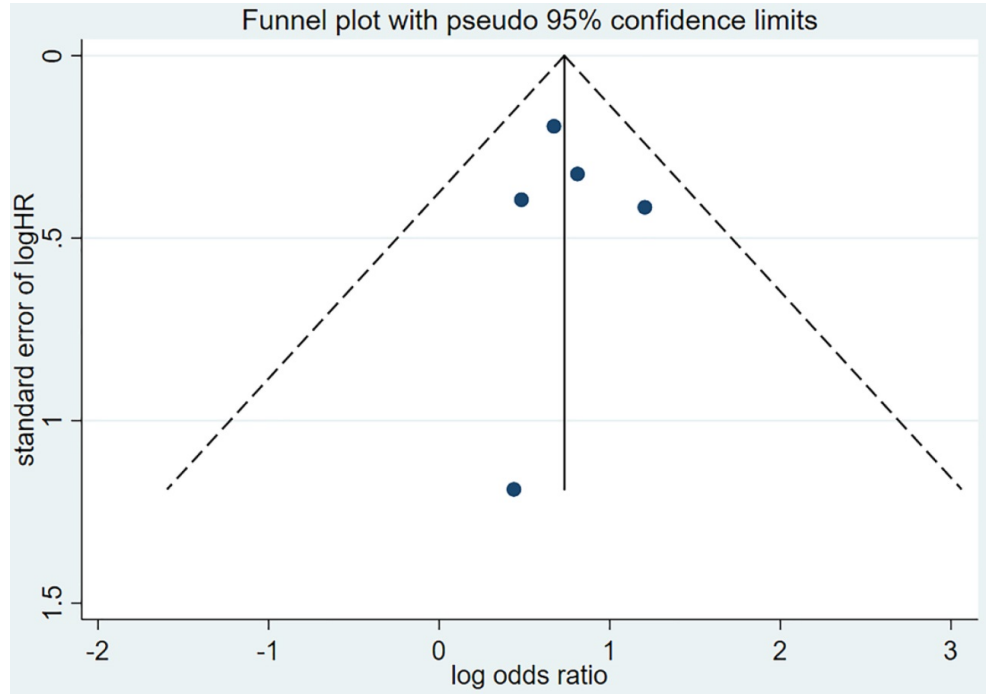

Figure 4 Funnel plot of hazard ratio for PFS. PFS=progression-free survival, HR=hazard ratio.

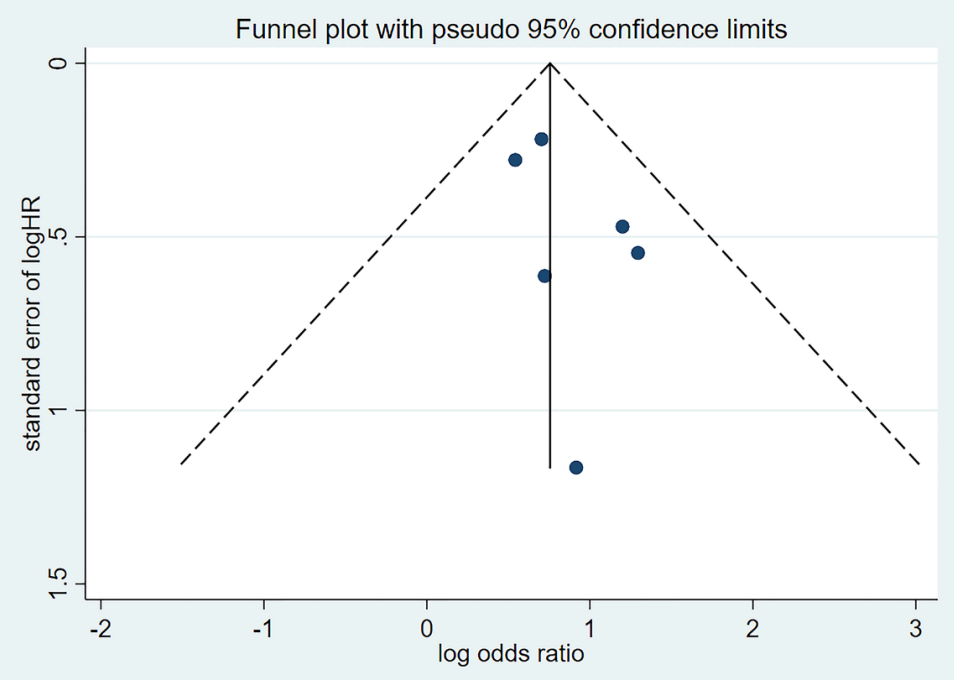

Figure 5 Funnel plot of hazard ratio for OS. OS=overall survival, HR=hazard ratio. 
The timing of surgery was also very important. The European Society for Medical Oncology (ESMO) practical guidelines[45] suggested that surgery should be performed at the time of maximal tumor response, generally 6-12 months after TKIs treatment for localized GISTs. However, optimal timing of surgery for advanced GISTs was still hard to ascertain. Keung et al.[46] recommended that cytoreductive surgery of residual metastatic disease should be considered no earlier than 6 months and no later than 2 years after TKIs initiation. Bischof et al. [47]suggested that patients with partial response (PR) and stable disease (SD) treated with TKIs therapy and surgery showed significantly prolonged PFS and OS compared with those with progressive disease (PD). Qiu et al.[36] also reported the similar results. These findings indicated that PR and SD may be the proper time for cytoreductive surgery. Although the prognosis of patients with PD receiving cytoreductive surgery was not satisfactory, no study has compared the survival of patients with PD between surgical treatment and TKIs treatment alone. Thus, selection of optimal candidates for cytoreductive surgery is also very difficult in clinical practice.

Up to date, no study has definitely evaluated the value of R2 cytoreductive surgery following TKIs treatment for advanced GISTs patients. All the enrolled six studies did not show the benefit of R2 resection through subgroup analysis due to extremely small sample size. Thus, the value of $\mathrm{R} 2$ resection was unclear, and the prolonged survival of patients with surgery (R0/R1/R2) may result from improved survival of patients receiving R0/R1 resection. Moreover, even if $\mathrm{R} 2$ resection could improve the prognosis of patients, enough attention should be paid to the degree of cytoreduction, because low cytoreduction proportion may not benefit the survival of patients with advanced GISTs. Unfortunately, the degree of cytoreduction was not described in the six studies included in our present study.

It is well known that type of gene mutation was associated with the prognosis of GIST patients[48, 49]. However, the impact of gene mutational status on the clinical outcomes of cytoreductive surgery is still unknown. Qiu et al.[36] reported that patients with primary c-KIT exon 11 rather than exon 9 mutation could benefit from cytoreduction surgery. Result of Park et al. [39] revealed that c-Kit exon 11 rather than exon 9 or wild-type was associated with longer PFS in the surgery group.

Continuation of TKIs therapy is very critical for advanced GIST patients after cytoreductive surgery. Both the National Comprehensive Cancer Network (NCCN) guidelines[50] and ESMO practical guidelines[45] recommend continuing imatinib mesylate (IM) as a post-resection treatment for advanced GIST patients. Zhang et al. [51] compared the clinical outcomes of advanced GIST patients receiving imatinib or switching to sunitinib after cytoreductive surgery based on 97 patients from 13 centers. They found that switching to sunitinib could significantly improve the PFS of patients compared with continuing imatinib treatment after R0 or cytoreductive surgery (30 months vs 12 months, $\mathrm{p}=0.009$ ), which indicated that sunitinib may be superior to imatinib for the patients after cytoreductive surgery. However, this should be confirmed through further studies based on larger populations.

So far, there was only one meta-analysis evaluated the role of surgery in patients with advanced GIST, which included 9 studies with 1416 patients. The pooled results revealed that surgery combined with TKIs therapy is associated with a better OS and PFS. However, patients in 4 studies included in this meta-analysis received surgery prior to imatinib therapy, which may result in bias and finally influence the evaluation of value of surgery in advanced GISTs patients. Because cytoreductive surgery before imatinib treatment for advanced GISTs patients was not recommended in the NCCN and ESMO guidelines[45, 50]. Therefore, our present meta-analysis strictly limited the inclusion criteria and updated the relevant literatures.

There are several limitations in our study. First, the sample size was relatively small; only six retrospective studies were analyzed. Second, the essential selection bias of the non-randomized and retrospective studies may result in incomparability between the two groups. For instance, the baseline characteristics in some studies were not homogeneous especially in physical condition, metastatic site, tumor size and number of metastases. Third, subgroup analysis concerning R2 resection, timing of surgery, and type of gene mutation, etc. was not performed due to data insufficiency in the included studies. To overcome these limitations, prospective randomized controlled trials based on large populations should be conducted.

\section{Conclusion}

In conclusion, this meta-analysis has demonstrated that surgical resection following TKIs therapy could prolong survival of patients with metastatic, recurrent or unresectable GISTs when compared with TKIs therapy alone. Cytoreductive surgery could be considered for selected advanced GIST patients after TKIs therapy. 


\section{Abbreviations}

GIST: gastrointestinal stromal tumor; TKIs: tyrosine kinase inhibitors; PFS: progression-free survival; OS: overall survival; HR: hazard ratio; $\mathrm{CI}$ : confidence interval; PDGFRA: platelet-derived growth factor receptor alpha; MeSH: Medical Subject Headings; S group: surgical resection group; NS group: TKIs treatment alone group; PR: partial response; $\mathrm{SD}$ : stable disease; $\mathrm{PD}$ : progressive disease; NOS: Newcastle-Ottawa Quality Assessment Scale; ASCO: American Society of Clinical Oncology; EORTC: European Organization for Research and Treatment of Cancer; ESMO: European Society for Medical Oncology; NCCN: National Comprehensive Cancer Network.

\section{Supplementary Material}

Supplementary figures and tables. http://www.jcancer.org/v10p5785s1.pdf

\section{Acknowledgments}

This study was supported in part by grants from the National Natural Scientific Foundation of China [NO. 31570907, 81300301, 81572306, 81502403].

\section{Authors' contributions}

GYH and LJQ screened and identified the search findings for potential eligible studies. Disagreements were settled by WF, ZGZ and LSS independently extracted the data from each included study. LX and WQ performed the statistical analyses and gave an interpretation of the results. GYH wrote the manuscript. ZHW and FF conceived, designed, supervised the study, and revised the manuscript. All authors read and approved the final version of the manuscript.

\section{Availability of data and materials}

All relevant data used and/or analyzed during the current study are available from the corresponding author on reasonable request.

\section{Competing Interests}

The authors have declared that no competing interest exists.

\section{References}

1. Reddy P, Boci K, Charbonneau C. The epidemiologic, health-related quality of life, and economic burden of gastrointestinal stromal tumours. Journal of clinical pharmacy and therapeutics 2007, 32(6):557-565

2. Miettinen M, Lasota J. Histopathology of gastrointestinal stromal tumor. Journal of surgical oncology 2011, 104(8):865-873

3. Chiang NJ, Chen LT, Tsai CR, et al. The epidemiology of gastrointestinal stromal tumors in Taiwan, 1998-2008: a nation-wide cancer registry-based study. BMC cancer 2014, 14:102.

4. Bauer S, Corless CL, Heinrich MC, et al. Response to imatinib mesylate of a gastrointestinal stromal tumor with very low expression of KIT. Cancer chemotherapy and pharmacology 2003, 51(3):261-265
5. Nilsson B, Bumming P, Meis-Kindblom JM, et al. Gastrointestinal stromal tumors: the incidence, prevalence, clinical course, and prognostication in the preimatinib mesylate era--a population-based study in western Sweden. Cancer 2005, 103(4):821-829.

6. Hirota S, Isozaki K, Moriyama Y, et al. Gain-of-function mutations of c-kit in human gastrointestinal stromal tumors. Science (New York, NY) 1998, 279(5350):577-580

7. Rubin BP, Singer S, Tsao C, et al. KIT activation is a ubiquitous feature of gastrointestinal stromal tumors. Cancer research 2001, 61(22):8118-8121.

8. Heinrich MC, Corless CL, Duensing A, et al. PDGFRA activating mutations in gastrointestinal stromal tumors. Science (New York, NY) 2003, 299(5607):708-710

9. Joensuu H, Fletcher C, Dimitrijevic S, et al. Management of malignant gastrointestinal stromal tumours. The Lancet Oncology 2002, 3(11):655-664.

10. Joensuu H, Vehtari A, Riihimaki J, et al. Risk of recurrence of gastrointestinal stromal tumour after surgery: an analysis of pooled population-based cohorts. The Lancet Oncology 2012, 13(3):265-274.

11. Casali PG, Le Cesne A, Poveda Velasco A, et al. Time to Definitive Failure to the First Tyrosine Kinase Inhibitor in Localized GI Stromal Tumors Treated With Imatinib As an Adjuvant: A European Organisation for Research and Treatment of Cancer Soft Tissue and Bone Sarcoma Group Intergroup Randomized Trial in Collaboration With the Australasian Gastro-Intestinal Trials Group, UNICANCER, French Sarcoma Group, Italian Sarcoma Group, and Spanish Group for Research on Sarcomas. Journal of clinical oncology : official journal of the American Society of Clinical Oncology 2015, 33(36):4276-4283

12. DeMatteo RP, Shah A, Fong $\mathrm{Y}$, et al. Results of hepatic resection for sarcoma metastatic to liver. Annals of surgery 2001, 234(4):540-547; discussion 547-548.

13. Roberts PJ, Eisenberg B. Clinical presentation of gastrointestinal stromal tumors and treatment of operable disease. European journal of cancer (Oxford, England : 1990) 2002, 38 Suppl 5:S37-38.

14. Demetri GD, von Mehren M, Blanke CD, et al. Efficacy and safety of imatinib mesylate in advanced gastrointestinal stromal tumors. The New England journal of medicine 2002, 347(7):472-480.

15. Blanke CD, Rankin C, Demetri GD, et al. Phase III randomized, intergroup trial assessing imatinib mesylate at two dose levels in patients with unresectable or metastatic gastrointestinal stromal tumors expressing the kit receptor tyrosine kinase: S0033. Journal of clinical oncology : official journal of the American Society of Clinical Oncology 2008, 26(4):626-632

16. Joensuu H, Roberts PJ, Sarlomo-Rikala M, et al. Effect of the tyrosine kinase inhibitor STI571 in a patient with a metastatic gastrointestinal stromal tumor. The New England journal of medicine 2001, 344(14):1052-1056.

17. Caram MV, Schuetze SM. Advanced or metastatic gastrointestinal stromal tumors: systemic treatment options. Journal of surgical oncology 2011, 104(8):888-895.

18. Heinrich MC, Owzar K, Corless CL, et al. Correlation of kinase genotype and clinical outcome in the North American Intergroup Phase III Trial of imatinib mesylate for treatment of advanced gastrointestinal stromal tumor: CALGB 150105 Study by Cancer and Leukemia Group B and Southwest Oncology Group. Journal of clinical oncology : official journal of the American Society of Clinical Oncology 2008, 26(33):5360-5367.

19. Blanke CD, Demetri GD, von Mehren $M$, et al. Long-term results from a randomized phase II trial of standard- versus higher-dose imatinib mesylate for patients with unresectable or metastatic gastrointestinal stromal tumors expressing KIT. Journal of clinical oncology : official journal of the American Society of Clinical Oncology 2008, 26(4):620-625.

20. Verweij J, Casali PG, Zalcberg J, et al. Progression-free survival in gastrointestinal stromal tumours with high-dose imatinib: randomised trial. Lancet (London, England) 2004, 364(9440):1127-1134.

21. Zaydfudim V, Okuno SH, Que FG, et al. Role of operative therapy in treatment of metastatic gastrointestinal stromal tumors. The Journal of surgical research 2012, 177(2):248-254

22. Guilhot F. Indications for imatinib mesylate therapy and clinical management. The oncologist 2004, 9(3):271-281.

23. Chu TF, Rupnick MA, Kerkela R, et al. Cardiotoxicity associated with tyrosine kinase inhibitor sunitinib. Lancet (London, England) 2007, 370(9604):2011-2019

24. Raut CP, Posner $M$, Desai J, et al. Surgical management of advanced gastrointestinal stromal tumors after treatment with targeted systemic therapy using kinase inhibitors. Journal of clinical oncology : official journal of the American Society of Clinical Oncology 2006, 24(15):2325-2331.

25. DeMatteo RP, Maki RG, Singer $S$, et al. Results of tyrosine kinase inhibitor therapy followed by surgical resection for metastatic gastrointestinal stromal tumor. Annals of surgery 2007, 245(3):347-352.

26. Mussi C, Ronellenfitsch U, Jakob J, et al. Post-imatinib surgery in advanced/metastatic GIST. is it worthwhile in all patients? Annals of oncology : official journal of the European Society for Medical Oncology 2010, 21(2):403-408.

27. Bauer S, Rutkowski P, Hohenberger $\mathrm{P}$, et al. Long-term follow-up of patients with GIST undergoing metastasectomy in the era of imatinib -- analysis of prognostic factors (EORTC-STBSG collaborative study). European journal of surgical oncology : the journal of the European Society of Surgical Oncology and the British Association of Surgical Oncology 2014, 40(4):412-419. 
28. Sym SJ, Ryu MH, Lee JL, et al. Surgical intervention following imatinib treatment in patients with advanced gastrointestinal stromal tumors (GISTs). J Surg Oncol 2008, 98(1):27-33.

29. An HJ, Ryu MH, Ryoo BY, et al. The effects of surgical cytoreduction prior to imatinib therapy on the prognosis of patients with advanced GIST. Ann Surg Oncol 2013, 20(13):4212-4218.

30. Stang A. Critical evaluation of the Newcastle-Ottawa scale for the assessment of the quality of nonrandomized studies in meta-analyses. European journal of epidemiology 2010, 25(9):603-605.

31. Liberati A, Altman DG, Tetzlaff J, et al. The PRISMA statement for reporting systematic reviews and meta-analyses of studies that evaluate healthcare interventions: explanation and elaboration. BMJ (Clinical research ed) 2009, 339:b2700.

32. Tierney JF, Stewart LA, Ghersi D, et al. Practical methods for incorporating summary time-to-event data into meta-analysis. Trials 2007, 8:16.

33. Higgins JP, Thompson SG, Deeks JJ, et al. Measuring inconsistency in meta-analyses. BMJ (Clinical research ed) 2003, 327(7414):557-560.

34. Begg CB, Mazumdar M. Operating characteristics of a rank correlation test for publication bias. Biometrics 1994, 50(4):1088-1101.

35. Egger M, Davey Smith G, Schneider M, et al. Bias in meta-analysis detected by a simple, graphical test. BMJ (Clinical research ed) 1997, 315(7109):629-634.

36. Qiu HB, Zhou ZG, Feng XY, et al. Advanced gastrointestinal stromal tumor patients benefit from palliative surgery after tyrosine kinase inhibitors therapy. Medicine (Baltimore) 2018, 97(2):e9097.

37. Gao X, Xue A, Fang Y, et al. Role of surgery in patients with focally progressive gastrointestinal stromal tumors resistant to imatinib. Scientific reports 2016, 6:22840.

38. Chang SC, Liao CH, Wang SY, et al. Feasibility and Timing of Cytoreduction Surgery in Advanced (Metastatic or Recurrent) Gastrointestinal Stromal Tumors During the Era of Imatinib. Medicine (Baltimore) 2015, 94(24):e1014.

39. Park SJ, Ryu MH, Ryoo BY, et al. The role of surgical resection following imatinib treatment in patients with recurrent or metastatic gastrointestinal stromal tumors: results of propensity score analyses. Annals of surgical oncology 2014, 21(13):4211-4217.

40. Bauer S, Hartmann JT, de Wit M, et al. Resection of residual disease in patients with metastatic gastrointestinal stromal tumors responding to treatment with imatinib. Int J Cancer 2005, 117(2):316-325.

41. Cho $\mathrm{H}$, Ryu $\mathrm{MH}$, Kim $\mathrm{KH}$, et al. Role of resection following focal progression with standard doses of imatinib in patients with advanced gastrointestinal stromal tumor: Results of propensity score analyses. Journal of Clinical Oncology 2018, 36(15)

42. Gronchi A. A Phase III Randomized Study Evaluating Surgery of Residual Disease in Patients With Metastatic Gastro-intestinal Stromal Tumor Responding to Imatinib Mesylate. Available from: URL:https://clinicaltrials.gov/ct2/show/nct00956072.2009.

43. Du CY, Zhou Y, Song C, et al. Is there a role of surgery in patients with recurrent or metastatic gastrointestinal stromal tumours responding to imatinib: a prospective randomised trial in China. Eur J Cancer 2014, 50(10):1772-1778

44. Xia L, Zhang MM, Ji L, et al. Resection combined with imatinib therapy for liver metastases of gastrointestinal stromal tumors. Surgery today 2010, 40(10):936-942.

45. Casali PG, Abecassis N, Bauer S, et al. Gastrointestinal stromal tumours: ESMO-EURACAN Clinical Practice Guidelines for diagnosis, treatment and follow-up. Annals of oncology : official journal of the European Society for Medical Oncology 2018.

46. Keung EZ, Fairweather M, Raut CP. The Role of Surgery in Metastatic Gastrointestinal Stromal Tumors. Current treatment options in oncology 2016, $17(2): 8$

47. Bischof DA, Kim Y, Blazer DG, et al. Surgical management of advanced gastrointestinal stromal tumors: an international multi-institutional analysis of 158 patients. Journal of the American College of Surgeons 2014, 219(3):439-449.

48. Joensuu H, Hohenberger P, Corless CL. Gastrointestinal stromal tumour. Lancet (London, England) 2013, 382(9896):973-983.

49. Corless CL, Barnett CM, Heinrich MC. Gastrointestinal stromal tumours: origin and molecular oncology. Nature reviews Cancer 2011, 11(12):865-878.

50. von Mehren M, Randall RL, Benjamin RS, et al. Soft Tissue Sarcoma, Version 2.2018, NCCN Clinical Practice Guidelines in Oncology. Journal of the National Comprehensive Cancer Network : JNCCN 2018, 16(5):536-563.

51. Zhang $\mathrm{X}$, Zhou $\mathrm{Y}, \mathrm{Wu} \mathrm{X}$, et al. Cytoreductive surgery for metastatic gastrointestinal stromal tumors followed by sunitinib compared to followed by imatinib-a multi-center cohort study. European journal of surgical oncology : the journal of the European Society of Surgical Oncology and the British Association of Surgical Oncology 2018. 